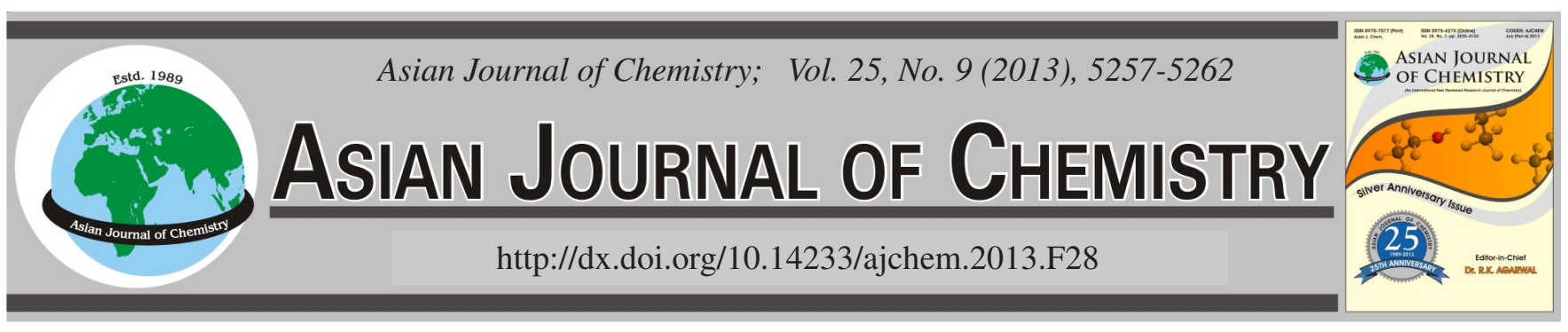

\title{
Prediction of Road Noise Caused by a Tyre in a Passenger Car Based on Transfer Path Analysis and Vibro-Acoustic Reciprocity $\dagger$
}

\author{
SungWook Hwang ${ }^{1, *}$, YungIn Kim ${ }^{1}$, JongHo Park ${ }^{2}$ and SAngKwon LeE ${ }^{2}$
}

${ }^{1}$ Nexen Tire Co., Ltd. 30 Yusan-Dong, Yangsan-Si, Kyungnam 626-230, Republic of Korea

${ }^{2}$ Department of Mechanical Engineering, Inha University, Yonghyun-dong, Namgu, Incheon 402-751, Republic of Korea

*Corresponding author: Fax: +82 55 3832313; Tel: +82 55 3705309; E-mail: ukhwang@ @exentire.co.kr

\begin{abstract}
The quantification of road noise is a challenging issue in vehicle noise-vibration-harshness (NVH) due to the extremely complicated transfer paths of road noise as well as the difficulty in identifying the input force experimentally from tyre-road interactions. The noise caused by tyres is divided into road noise and pattern noise. Although pattern noise is the result of the tyre's pattern shape, in which the frequency band is $>500 \mathrm{~Hz}$, road noise involves interactions between the tyre and vehicle body. This paper reports the quantitative analysis of road noise caused by interactions between the tyre and road parameters. The chassis dynamometer, which was equipped with a $10 \mathrm{~mm} \times 10 \mathrm{~mm}$ square cleat in the semi-anechoic chamber, was used to identify road noise and the tyre spindle forces were measured using a load cell. The vibro-acoustic transfer function between the ear position and wheel center was measured using the vibro-acoustic reciprocity method.
\end{abstract}

Key Words: Vibro-acoustic reciprocity, Road noise, Transfer path analysis.

\section{INTRODUCTION}

The identification of vehicle noise is a basic demand. The main contributions of automotive interior noise can be divided into powertrain noise, intake/exhaust noise and road noise caused by contact with the road surface and tyre. Among these, road noise has a major effect on automotive interior noise $\mathrm{e}^{1,2}$ because powertrain noise and intake/exhaust noise have been improved through many studies ${ }^{3}$.

Road noise generally has a peak at 60-65 dBA and decreases when the frequency is increased to more than $250 \mathrm{~Hz}$. The noise level at the frequency band over $1 \mathrm{kHz}$ is lower than the noise level at $300 \mathrm{~Hz}(>15 \mathrm{dBA})$, because the noise source that generates interior noise is low ${ }^{4}$. To analyze the influence of road noise related to the tyre and road, the transfer function of a car was measured using vibro-acoustic reciprocity and the excitation force of the tyre was estimated using the cleat excitation method. Road noise was estimated from the measured excitation force and transfer function and an experimental tyre change and characteristics was performed using 3 tyres with a range of mechanical vibration features. This paper reports the direction of road noise reduction development of a real car.

\section{THEORY}

Transfer path analysis: In vehicles, which are comprised of multiple components, noise is transferred to the inside or outside through a variety of paths. In particular, in the case of structure borne noise, the vibration caused by an interaction of the contact surface of road and tyre is transferred through the path of the vehicle and body, frames, panels, etc. through vibrations. Because the vibration appears in the form of noise inside, there are a range of noise mechanisms. In regard to noise, TPA (Transfer Path Analysis) is used widely to determine the path of inner noise and its contribution. The theoretical expression for transfer path analysis about structure-borne noise is as follows.

$$
\mathrm{P}_{\text {response }}^{\text {operation }}=\sum_{\mathrm{i}=1}^{\mathrm{n}} \mathrm{P}_{\mathrm{i}}=\sum_{\mathrm{i}=1}^{\mathrm{n}} \mathrm{F}_{\mathrm{i}}^{\mathrm{cal}} \times \frac{\mathrm{p}^{\text {response }}}{\mathrm{F}_{\mathrm{i}}^{\text {input }}}
$$

where $\mathrm{P}_{\text {response }}^{\text {operation }}$ that occurs in the room means structure borne noise, $\mathrm{F}_{\mathrm{i}}^{\mathrm{cal}}$ is the exciting force on the transfer path $\mathrm{i}$ acting point and $\mathrm{p}^{\text {response }} / \mathrm{F}_{\mathrm{i}}^{\text {input }}$ means the vibro-acoustic transfer function between the $\mathrm{i}$ point and compartment pressure measurement. The structure borne noise is a product of an exciting force acting on each transfer path and the vibro-acoustic transfer function between the input point and response point. Accordingly, when driving, it is possible to estimate the contribution to the response point of each path using an exciting force and to derive. The vibro-acoustic transfer function of the exciting force and the vehicle body while the operation system is the core of transfer path analysis. For example, how

$†$ Presented to the International Rubber Conference (IRC-2012), May 21-24, 2012, Jeju, Republic of Korea 
to determine the exciting force at the tip of a tyre or knuckle is to attaching a force transducer or to measure the road shape directly and estimate it indirectly using vibration acceleration on the transfer path. The direct method is difficult because it is important to attach sensors at the tip of the tyre or knuckle or calculate the exciting force by Hertz impact theory after scanning the road shape ${ }^{5}$. For these reasons, the indirect method, which measures the vibration acceleration on the transfer path, is mainly used. The indirect method uses the dynamic stiffness method and inverse matrix method depending on the characteristics of the test specimen. In this study, the exciting force on the transfer path was not estimated experimentally but the exciting force on the knuckle was measured directly using a load cell. Similarly, the difficulties regarding the predictions of an exciting force and the experimental and mathematical errors can be reduced when applying a directly measured exciting force to transfer path analysis.

Vibro-acoustic reciprocity: Two methods can be used to measure the vibro-acoustic transfer function. One is to use an impulse hammer and the other is to use a loud speaker based on the contrary principle. Vibro-acoustic reciprocity is about the relationship between the responses of the panel about the sound field formed by structure borne noise and the sound source, which occurs when the external force acts on the structure (Fig. 1). Through vibrations of the panel, which occurs when an exciting force is applied to the $r_{i}$ point of a structure, the acoustic pressure formed on the $r_{i}$ point and the vibration velocity on the structure $r_{i}$ point by sound source at the $r_{k}$ point without an external force has correlations, such as eqn. (2)

$$
\frac{P\left(r_{k}\right)}{F\left(r_{i}\right)}=-\frac{v\left(r_{i}\right)}{Q\left(r_{k}\right)}
$$

where $\mathrm{P}\left(\mathrm{r}_{\mathrm{k}}\right)$ and $\mathrm{Q}\left(\mathrm{r}_{\mathrm{k}}\right)$ mean the sound pressure and pole volume velocity, respectively, at the point of $r_{k}$ and $F\left(r_{i}\right)$ and $v\left(r_{i}\right)$ mean the exciting force and vibration velocity, respectively, at the $r_{i}$ point.
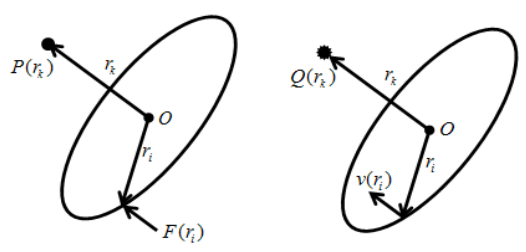

Fig. 1. Illustration for the application of reciprocity theory to interior noise analysis

The modeling of vibro-acoustic reciprocity in a vehicle is shown in Fig. 2.

\section{EXPERIMENTAL}

Experimental test of tyre transfer function: To measure the frequency response function of tyres, the test tyres were suspended to the tyre modal test equipment and force, a quarter of Hyundai YF Sonata 2.0 LPG model (approximate 4500 N), was applied, as shown in Figs. 3 and 4. The sensors were attached to the point between the road surface and tyres as closely as possible. Subsequently, the frequency response function was obtained by acting on the $\mathrm{Z}$ direction and $\mathrm{X}$ direction of the knuckles by a hammer. The frequency response functions of the three different tyres were calculated. Table- 1 lists the devices of the tyre frequency response function test. Assume that the shaft connected to the wheel of tyres is considered to be a knuckle of real automobiles and front tyres vibro acceleration by the impulse hammer is then used to obtain the frequency response function, $\mathrm{H}_{\mathrm{ij}}$, of eqn. (3).

$$
H_{i j}=\frac{X_{j}}{F_{i}},[H]_{\text {Tire-Knuclde }}=\left[\begin{array}{ll}
\frac{\ddot{x}_{t r}}{f_{k x}} \frac{\ddot{x}_{t t}}{f_{k x}} \\
\frac{\ddot{x}_{t r}}{f_{k z}} \frac{\ddot{x}_{t t}}{f_{k z}}
\end{array}\right]
$$

where $F_{i}$ is the input force at point $i$ and $X_{j}$ is the output vibro acceleration. $\mathrm{f}_{\mathrm{kx}}$ is the force in the $\mathrm{X}$ direction and $\mathrm{f}_{\mathrm{kz}}$ is the force in the $\mathrm{Z}$ direction at the knuckle $(\mathrm{k})$ and $\ddot{\mathrm{x}}_{\mathrm{tr}}$ and $\ddot{\mathrm{x}}_{\mathrm{tt}}$ are the response acceleration of the radial and tangential direction, respectively. The resolution for the test was $1 \mathrm{~Hz}$ and the sampling frequency was $2048 \mathrm{~Hz}$.

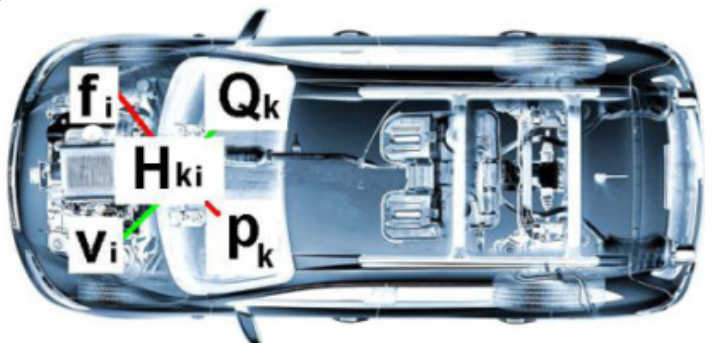

Fig. 2. Illustration for modeling of vibro-acoustic reciprocity in a vehicle

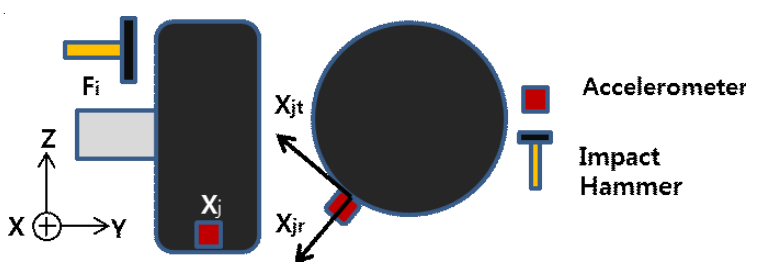

Fig. 3. Pictorial explanation of the modal testing of a tyre
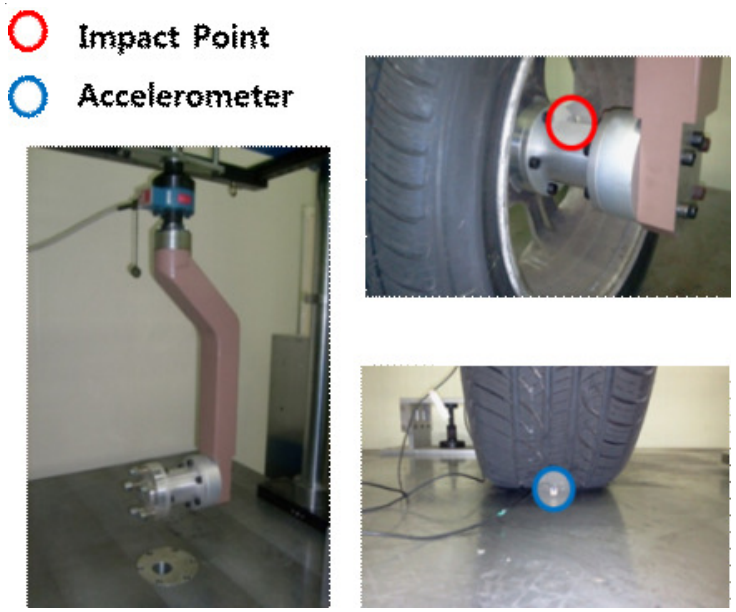

Fig. 4. Excitation and response point for the modal test of a tyre

Fig. 5 shows the three tyre's frequency response functions and Figs. 6-8 show the results classified into the three types of characteristics. Fig. 6 presents a section of the Boom noise, which has a frequency range of 20 200 Hz. All frequency ranges have an error within $1 \mathrm{~dB}$, except for the $180 \mathrm{~Hz}$ band. 
Fig. 7 shows a section of the cavity noise, ranging from 200 and $250 \mathrm{~Hz}$. The frequency showed a peak at approximately $220 \mathrm{~Hz}$, representing the best characteristics of a car tyre. Tyre A had the largest level with $110 \mathrm{~dB}$ and the peaks of Tyre B and Tyre $\mathrm{C}$ were $5 \mathrm{~dB}$ lower than A. Fig. 8 presents a section of rumble noise, had a frequency range of 250-500 Hz. Tyre $\mathrm{B}$ had the highest noise in the entire range except at approximately $450 \mathrm{~Hz}$. Tyre A, which had the highest peak in the cavity noise section, showed a relatively low level at approximately $450 \mathrm{~Hz}$. The trend of the noise can be predicted from the three frequency bands that could be observed during the actual vehicle load.

When driving, Tyre A, which showed the best representing cavity noise properties was expected to have the highest sound pressure level at approximately $220 \mathrm{~Hz}$. Other frequency bands, while driving, could indicate different results ${ }^{1}$. These characteristics are quite influential on the factors in designing tyres that enormously affect the actual road noise while driving. In this study, the entire road-noise resulting from the noise

\begin{tabular}{ll}
\multicolumn{2}{c}{ TABLE-1 } \\
& $\begin{array}{c}\text { DEVICES OF THE TIRE FREQUENCY } \\
\text { RESPONSE FUNCTION TEST }\end{array}$ \\
\hline Device & Device Name \\
\hline Equipment & Equipment \\
Impulse Hammer & Impulse Hammer \\
Accelerometer & Accelerometer \\
FFT Analyzer & FFT Analyzer \\
Data Acquisition Module & Data Acquisition Module \\
\hline
\end{tabular}

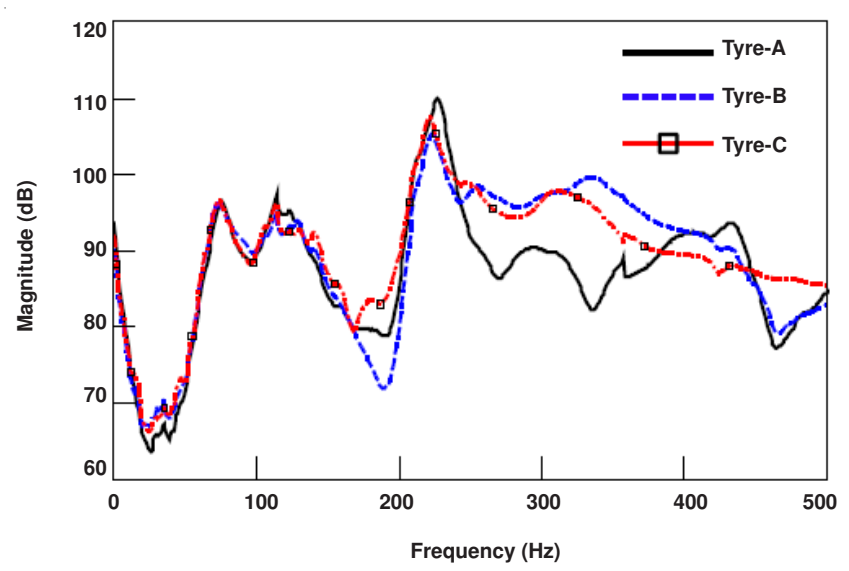

Fig. 5. Frequency response function of three tyres

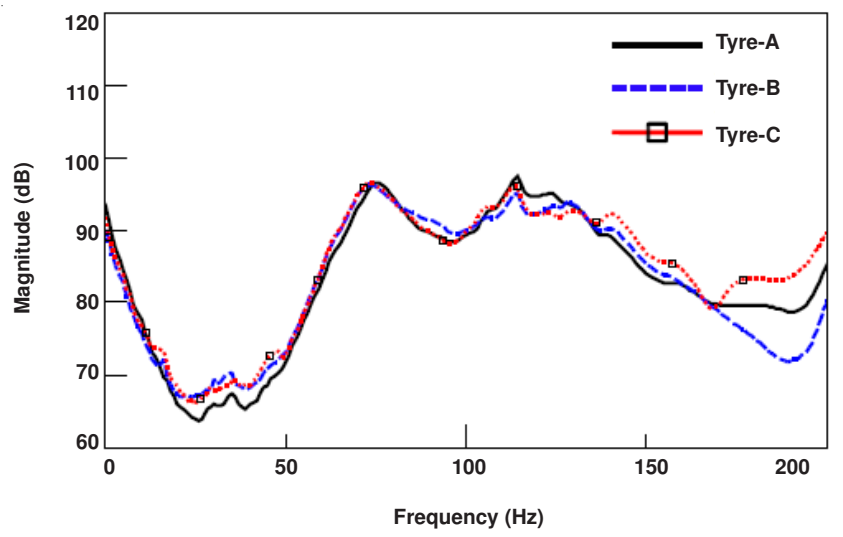

Fig. 6. Frequency response function of three tyres $(20-200 \mathrm{~Hz})$

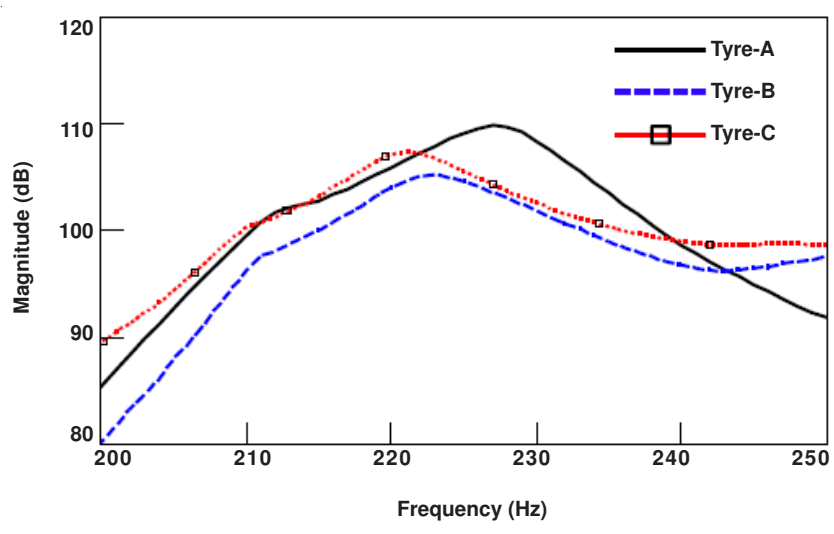

Fig. 7. Frequency response function of three tyres $(200-250 \mathrm{~Hz})$

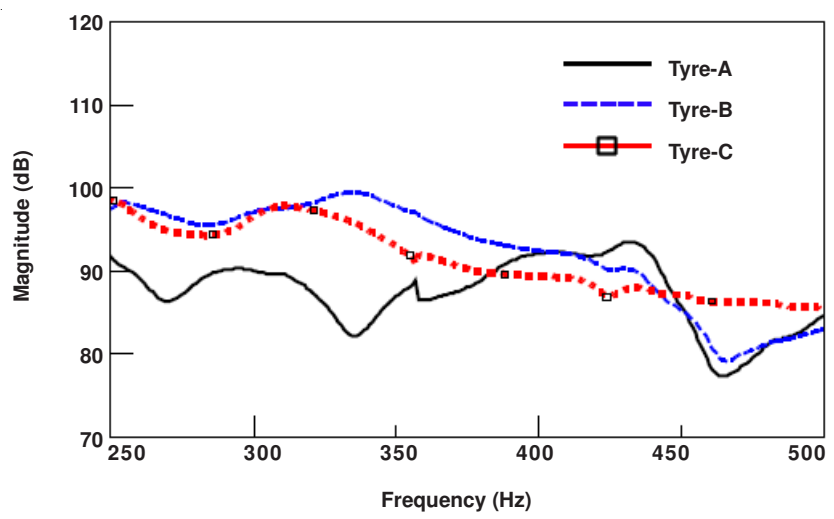

Fig. 8. Frequency response function of three tyres $(250-500 \mathrm{~Hz})$

of structural vibration of vehicle (structure-borne) transfer were analyzed and quantified. The noise from structural vibration of the vehicle occurs after exposing the vehicles to the three types of tyres of different frequency characteristics

Vibro-acoustic transfer function measurement: When measuring with the vibro-acoustic transfer function using an acoustical reciprocity principle, omni-directional sound sources need to be used as excitation sources but these sources generate low frequency, should have sufficient power to excite the body of a car. The loud speaker using the measurement is the medium frequency of $20-800 \mathrm{~Hz}$, which can induce acoustic excitation and is installed in the drive seat (Fig. 9). In addition, a 3-axis acceleration sensor was set up at the central part of the car wheels to chose the transfer path. Using a loud speaker, the vibro-acoustic transfer function between the indoor seat and central part of a car wheel was measured from the response acceleration generated under sound pressure excitation. Tyres, as excitation sources, were carried off and set up in the air using lifting equipment for the next measurement. If the measurement is taken under contact with a road surface while setting up the tyre, it would be difficult to test precisely due to an interaction with the road surface and the involved transfer characteristic of the tyre acts as an excitation source. To eliminate these effects, the test maintained its insulation condition using lifting equipment to detach the tyre from the road surface and remove the transfer characteristic error through an interaction between the vehicle and lifting equipment. All measurements were proceeded in a semianechoic room for organization in a free sound field. Table- 2 specifies the equipment lists related to the measurements. 

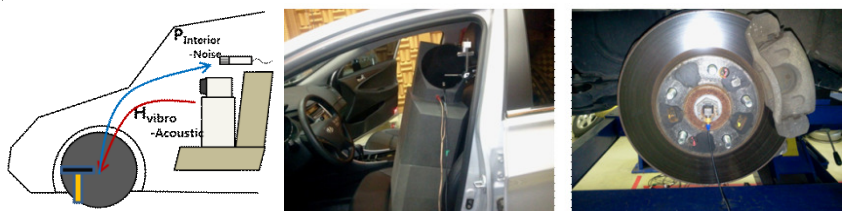

Fig. 9. Experimental set-up for the vibro-acoustic transfer function

\begin{tabular}{ll} 
TABLE-2 \\
& $\begin{array}{l}\text { DEVICES OF THE VIBRO-ACOUSTIC } \\
\text { TRANSFER FUNCTION TEST }\end{array}$ \\
\hline Device & Device Name \\
\hline Vehicle & Hyundai YF SONATA 2.0 LPG \\
Acoustic Exciter & LMS Q-Source \\
Accelerometer & Endevco 65-10 Triaxial ICP \\
FFT Analyzer & LMS Test.lab 10B \\
Data Acquisition Module & LMS SCASDAS Mobile 32CH \\
\hline
\end{tabular}

The vibro-acoustic transfer function, which is between an ear point in a cabin and the wheel center, has an input signal, which is the sound power generated by a loud speaker. This has an output signal in X-direction acceleration and Z-direction acceleration, which are generated by a loud speaker. Equation (3) has the following form:

$$
\left[\mathrm{H}_{\mathrm{VA}}\right]=\left[\begin{array}{l}
\frac{\ddot{\mathrm{x}}_{\text {WheelCenter/x}}}{\mathrm{Q}_{\text {cabin }}} \\
\frac{\ddot{\mathrm{x}}_{\text {WheelCenter } / \mathrm{z}}}{\mathrm{Q}_{\text {cabin }}}
\end{array}\right]
$$

The vibro-acoustic transfer function of eqn. (3) can be expressed by eqn. (4) to be applied to the system response function.

$$
\left[\mathrm{P}_{\text {cabin }}\right]=\left[\mathrm{H}_{\mathrm{VA}}\right][\mathrm{f}]_{\text {Wheel Center }}
$$

where $\mathrm{P}_{\text {cabin }}$ is the sound pressure level measured in a cabin and $f_{\text {wheel center }}$ is the exciting force generated in the wheel center.

Fig. 10 shows the vibro-acoustic transfer function between the ear point in the cabin and wheel center. The resolution was $1 \mathrm{~Hz}$ and the sampling frequency was $2048 \mathrm{~Hz}$.

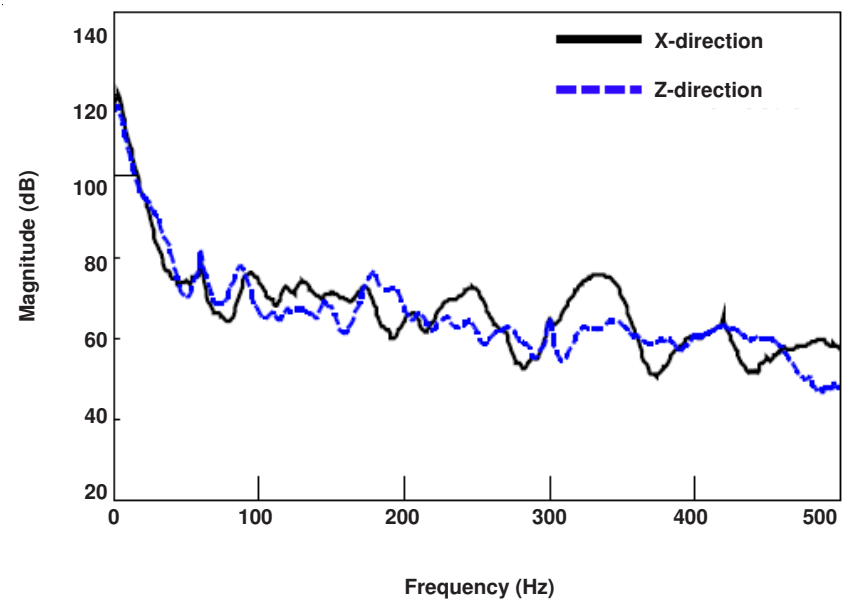

Fig. 10. Vibro-acoustic transfer function between the wheel center and driver's ear point

Vibratory force measurements through the cleat driving test: As shown in Figs. 11 and 12, after the experimental tyre was mounted on a chassis dynamometer with a $10 \mathrm{~mm} \times 10$ $\mathrm{mm}$ size cleat attached, a force of $4500 \mathrm{~N}$ was applied in the vertical direction as 1/4 weight of the experimental vehicle. Under these conditions, after driving at a constant speed of $60 \mathrm{~km} / \mathrm{h}$, the force of the wheel center was applied using a quarter vehicle model equipped with load cells. Equipment that can measure the vibrating force of the wheel center could not be used because the actual vehicle on the chassis dynamometer was used. In many studies, instead of measuring the source of the vibratory force directly, the predictive vibratory force was applied using the stiffness method or inverse method in the course of transfer path analysis. This process required considerable time and labor, which involved experimental error and error in the prediction process. Therefore, applying measure vibratory force directly can achieve high reliability in transfer path analysis. This process involves vibrating the entire frequency band, as a vibrating force with the tip of the tyre turn impulse signal that measures the exciting force through the chassis dynamometer driving test equipment with a cleat and analyzing the load noise. Through the experiments, the vibrating force of the wheel center of driving was measured in the driving direction (X-direction) and vertical direction (Y-direction). Fig. 13 provides data on the measured vibrating force on the wheel center with three types of tyres. The driving direction has a peak of $157 \mathrm{~dB}$ at a $80 \mathrm{~Hz}$ area, which is approximately $80 \mathrm{~N}$. The vertical direction has a peak of 150 $\mathrm{dB}$, which is approximately $35 \mathrm{~N}$. In general, the X-direction (driving direction) has a higher level than the Z-direction (vertical direction), which shows that the vibrating force has higher values in the driving direction with real driving.

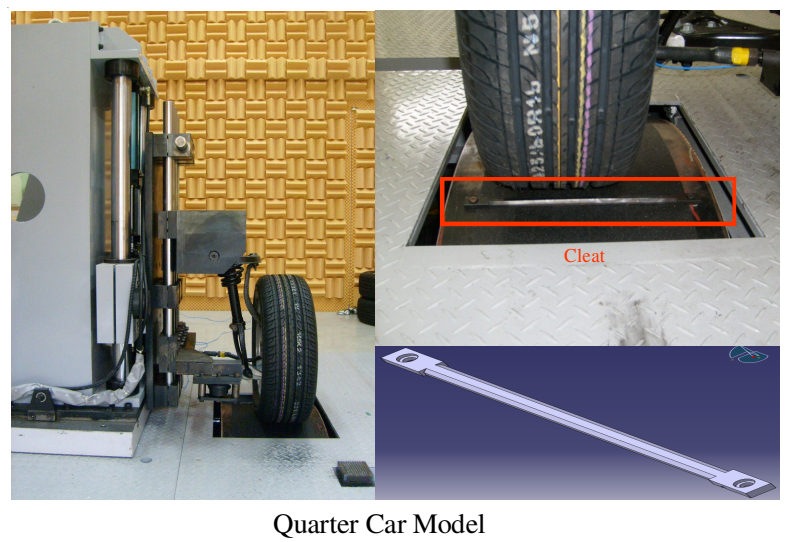

Fig. 11. Experimental set-up of a rolling cleat to measure the excitation force in a wheel-center

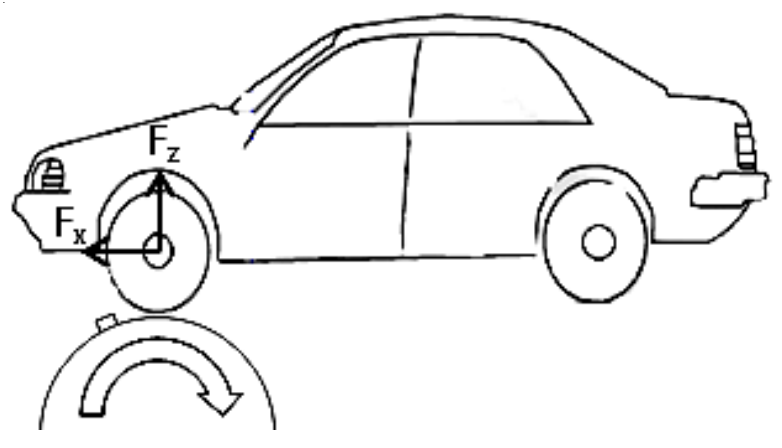

Fig. 12. Measurement of the excitation force based on a cleat test 

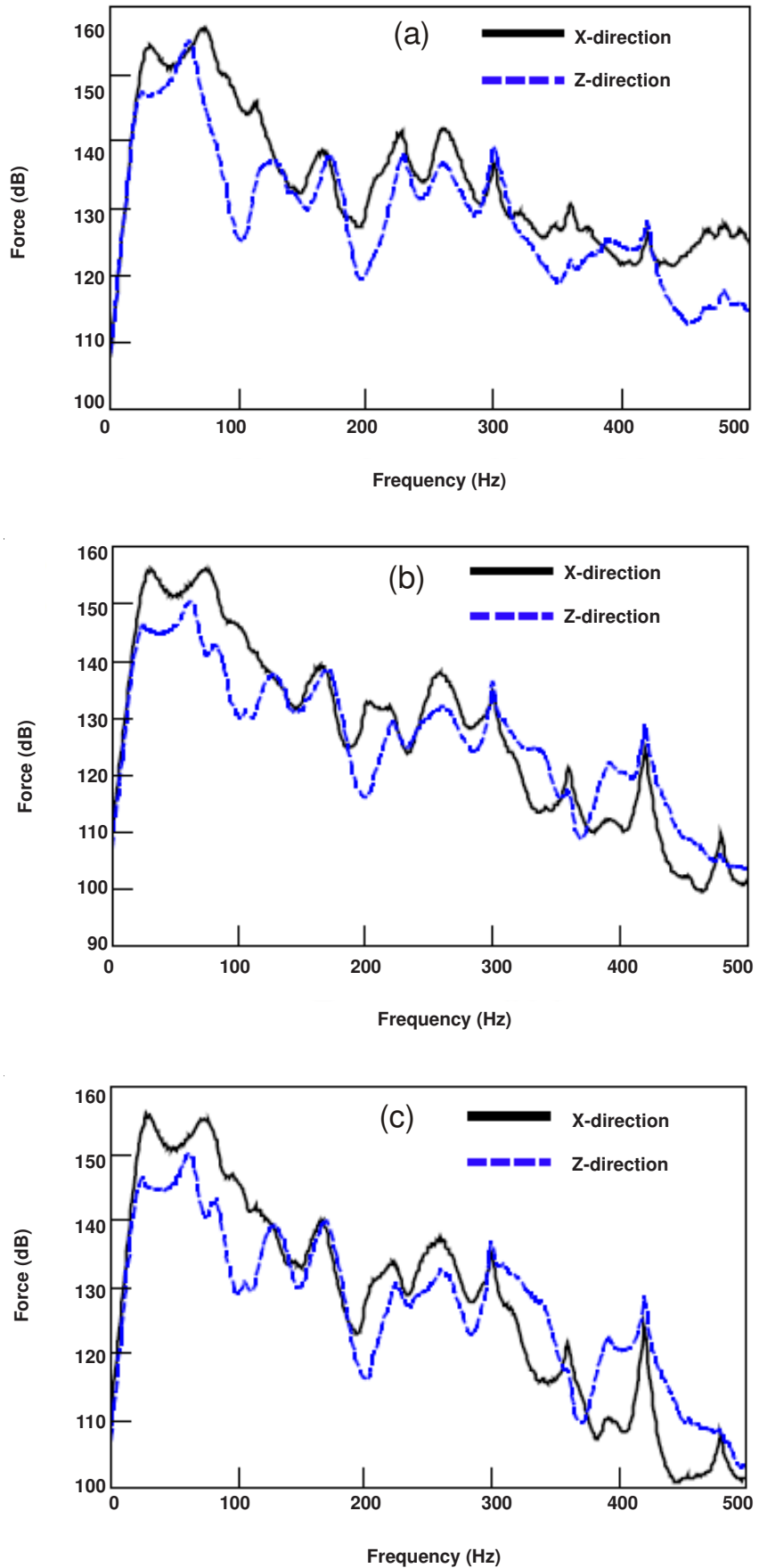

Fig. 13. Measured wheel center force for the 3 type of tyres. (a) Tyre-A (b) Tyre-B (c) Tyre-C

Fig. 14 (a) and (b) compare the excitation force at the $\mathrm{x}$ direction with that in the $\mathrm{z}$ direction on the wheel center. Tyres $\mathrm{A}, \mathrm{B}$ and $\mathrm{C}$, had a peak point at $145 \mathrm{~dB}, 133 \mathrm{~dB}$ and $135 \mathrm{~dB}$, respectively, at $220 \mathrm{~Hz}$, indicating tyre cavity features. This matches the tyre cavity characteristics of the past tyre transfer characteristic test. In other words, the excitation force at the wheel center caused by an interaction between the tyre and road has relationship with the transfer characteristics of the tyre. At a rumble noise band $>250 \mathrm{~Hz}$, it appears to be different if the forces are expressed as decibel $(\mathrm{dB})$. On the other hand, when the forces are converted to Newtons $(\mathrm{N})$, they have a maximum $8 \mathrm{~N}$ peak and $3 \mathrm{~N}$ at the other band. Therefore, they are not associated with the tyre characteristics.
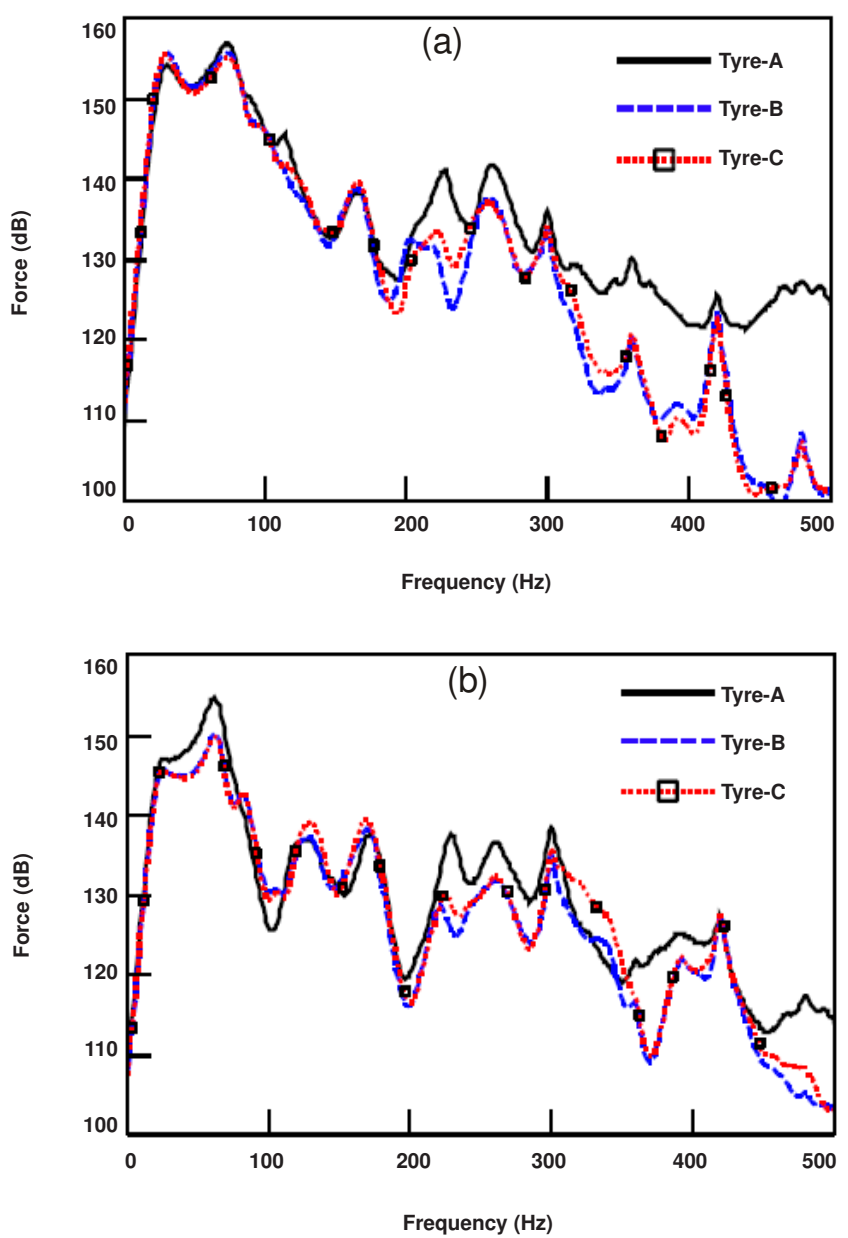

Fig. 14. Comparison of the excitation forces measured on the wheel center. (a) $\mathrm{x}$-direction (b) z-direction

Measurement of the car interior sound pressure level using a cleat operation test: Three types of tyres were installed to measure the car interior sound pressure level at the operating chassis dynamo attached to the cleat test car (Fig. 15). The chassis dynamo using test can operate the front left tyre of a car. The car interior sound pressure level was measured at the driver's ear position at $60 \mathrm{~km} / \mathrm{h}$ when the power train was stopped.

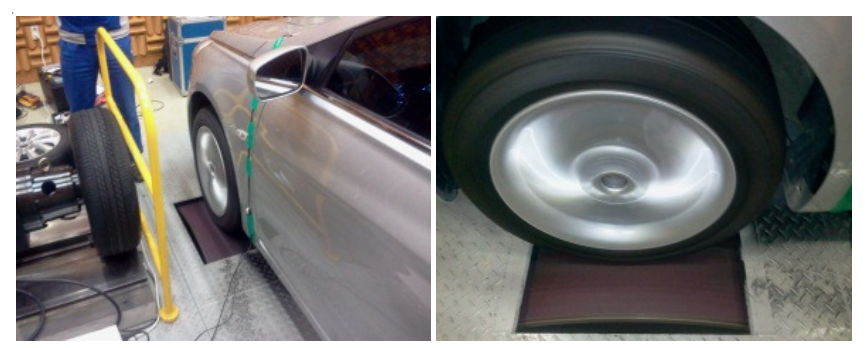

Fig. 15. Photo explanation of the rolling cleat test to measure the sound pressure in a vehicle

The reason for the test when the power train was stopped was the increased reliability of quantitative analysis by eliminating the noise of the power train and the intake-exhaust that accounts for diverse operating noise. The test examined 3 types of tyres with a $1 \mathrm{~Hz}$ resolution and sampling frequency of $2048 \mathrm{~Hz}$. 
Analysis of road noise and contribution: To analyze the road noise generated when operating the front left tyre, the excitation force of the wheel center was measured using a cleat operation test and structure-acoustic transfer function according to eqn. 4. Fig. 16 compares the measured interior noises of the 3 types of tyre. Fig. 17 shows the road noise analysis result estimated using the cleat excitation transfer path analysis of eqn. 4 at the same test. The difference between the measured and estimated data is the structure-born noise related to the left tyre that ignores air-born noise and right tyre excitation. To this result, the difference in the interior noise related characteristics of the tyre and the difference in the estimated interior noise have the same frequency and amplitude.

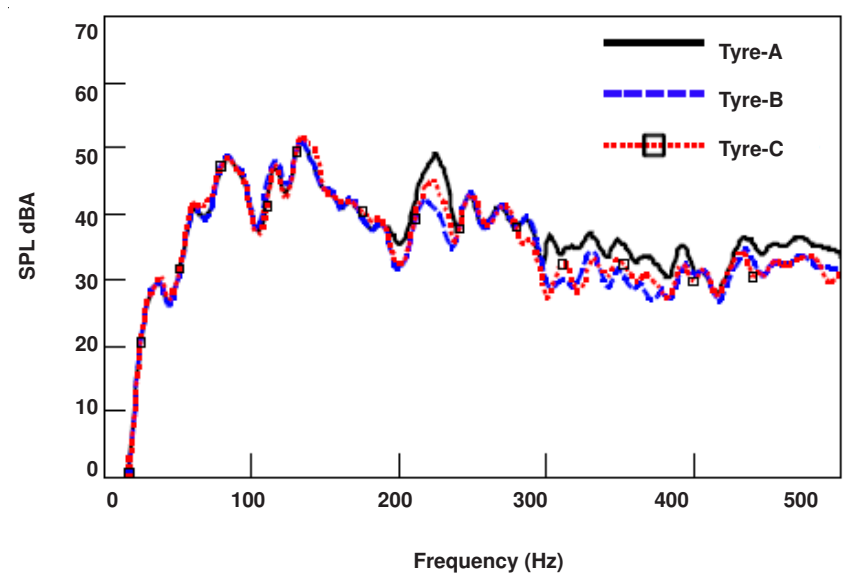

Fig. 16. Comparison of the measured interior noise in a vehicle with three different types of tyres.

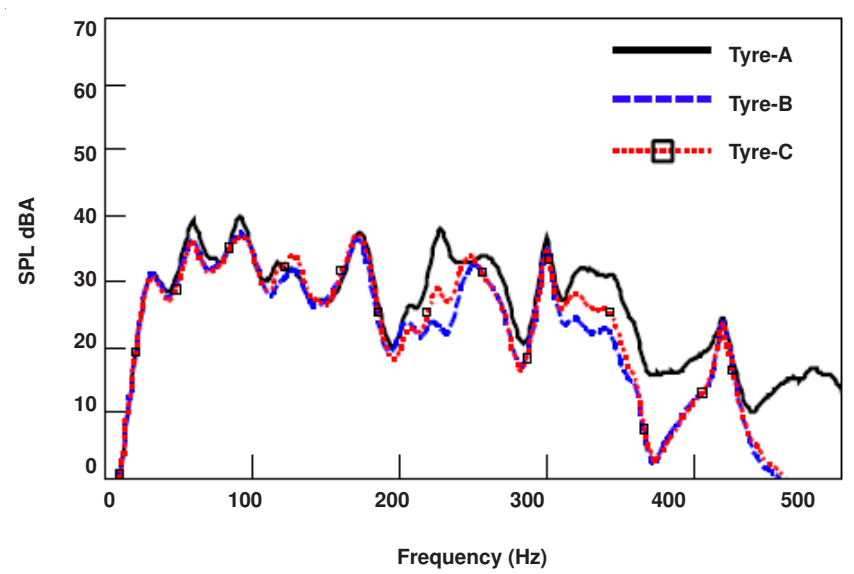

Fig. 17. Comparison of the estimated interior noise in a vehicle with three different types of tyres

Table- 3 shows the peak value of the boom, cavity and rumble noise band at the measured sound pressure level. In the boom noise band, 3 tyres have a similar level, but the cavity and rumble noise band have a different level. Table- 4 lists the road noise of each band estimated by transfer path analysis. In the boom and rumble noise band, the 3 tyres have a sound pressure level with a similar peak and the cavity noise band peak difference was a maximum $14 \mathrm{~dB}$. The results of road noise analysis showed a significant difference, which was similar to the tyre transfer characteristics of the band-generated cavity noise. The right wheel was operated simultaneously with a left wheel operation and both the noise generated in this process and the operating noise of the chassis dynamometer were not considered.

TABLE-3

MEASURED SPL PEAK LEVEL OF EACH BAND

\begin{tabular}{cccc}
\hline Tire type & $\begin{array}{c}\text { Boom } \\
(20-200 \mathrm{~Hz})\end{array}$ & $\begin{array}{c}\text { Cavity } \\
(200-250 \mathrm{~Hz})\end{array}$ & $\begin{array}{c}\text { Rumble } \\
(250-500 \mathrm{~Hz})\end{array}$ \\
\hline $\mathrm{A}$ & $52 \mathrm{dBA}$ & $42 \mathrm{dBA}$ & $43 \mathrm{dBA}$ \\
$\mathrm{B}$ & $52 \mathrm{dBA}$ & $37 \mathrm{dBA}$ & $35 \mathrm{dBA}$ \\
$\mathrm{C}$ & $52 \mathrm{dBA}$ & $40 \mathrm{dBA}$ & $35 \mathrm{dBA}$ \\
\hline
\end{tabular}

TABLE-4

ESTIMATED ROAD NOISE PEAK LEVEL OF EACH BAND

\begin{tabular}{cccc}
\hline Tire type & $\begin{array}{c}\text { Boom } \\
(20-200 \mathrm{~Hz})\end{array}$ & $\begin{array}{c}\text { Cavity } \\
(200-250 \mathrm{~Hz})\end{array}$ & $\begin{array}{c}\text { Rumble } \\
(250-500 \mathrm{~Hz})\end{array}$ \\
\hline A & $40 \mathrm{dBA}$ & $40 \mathrm{dBA}$ & $40 \mathrm{dBA}$ \\
B & $40 \mathrm{dBA}$ & $30 \mathrm{dBA}$ & $40 \mathrm{dBA}$ \\
C & $40 \mathrm{dBA}$ & $26 \mathrm{dBA}$ & $40 \mathrm{dBA}$ \\
\hline
\end{tabular}

\section{Conclusion}

The road noise was quantified using the experimental test, excluding the dynamic stiffness method and matrix inversion method, which are the existing theory of transfer path analysis. In addition, different transmission characteristics of the tyre and exciting force of the wheel center were analyzed and the predicted road noise and vehicle noise were compared. The tyre, which has higher characteristic cavity noise, had a higher level of exciting force and sound pressure level in the vicinity of $200-250 \mathrm{~Hz}$.

A more reliable mechanism of road noise analysis was also established using a chassis dynamometer rolling test with a cleat without powertrain and intake/exhaust noise. An expansion of this study with actual road load noise analysis is currently underway.

\section{REFERENCES}

1. U. Sandberg and J.A. Ejsmont, Tyre/Road Noise Reference Book, Informex, Swedeen, pp. 43-154 (2002).

2. S.J. Kim and S.K. Lee, KSNVE07S-18-04, pp. 501-506 (2007).

3. I.W. van Keulen and IR.M. Duskov, IPG Project report DWW-2005022 (2005).

4. M. Harrison, Vehicle Refinement: SAE International, pp. 179-181.

5. T. Fujikawa, H. Koike and Y. Oshino, Inter-Noise Congress, pp. 862865 (2003). 